\title{
Analysis of Service Quality and Resident Supervision in Accordance with Hospital Accreditation Standards
}

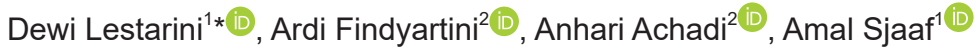 \\ ${ }^{1}$ Department of Health Policy and Administration, Faculty of Public Health, Universitas Indonesia, Depok, Indonesia; ${ }^{2}$ Department \\ of Medical Education, Faculty of Medicine, Universitas Indonesia, Depok, Indonesia
}

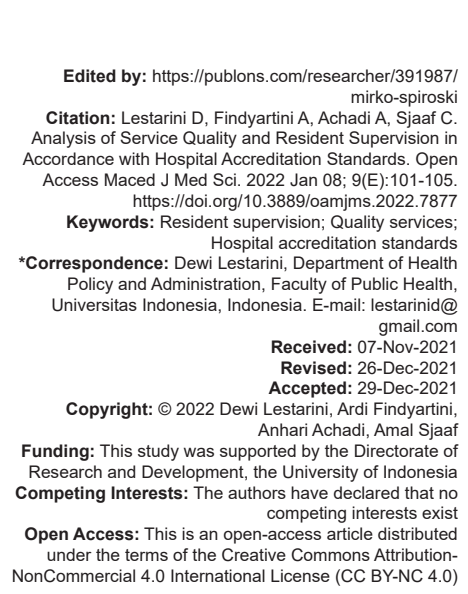

Introduction

Hospital accreditation needs to be accomplished in order to reach service excellence, which closely related to patient safety and safe surgery. Particularly in teaching hospitals, supervision plays an important role, where most services are carried out by residents. Based on the Fatmawati General Hospital data, it is found that $6.5 \%$ of the residents were unsupervised, hence the medical record filling were not met the standards [1].

The definition of supervision in medical education is one-to-one encounters aimed at promoting competence and reflective practice [2]. The purpose of supervision is to enhance the development and performance of the trainees. and to ensure the trainees can perform competently. Supervision must address the complexity and uniqueness of the problems to generate solutions or options that are the best fit [2]. Harms et al. divided supervision into five stages: (1) students are not allowed to do work, (2) students may do work with direct assistance, (3) students may do work with indirect assistance, (4) students are allowed to do work independently, and (5) students can assist younger students in carrying out activities [3].

Concerning residents' supervision, there have been strong recommendations for the use of workplace-based assessment, such as the Directly Observed Procedural Skill (DOPS), Mini Clinical Evaluation Exercise for Trainee (Mini-CEX), and $360^{\circ}$ evaluation [4]. Currently, common tools used are the Mini-Cex, Ottawa Clinical Assessment Tool, DOPS, Case-based Discussion, and Multi Source or $360^{\circ}$ feedback, such as the Mini Peer Assessment Tool [5].

In the field of Obstetrics and Gynecology, safe surgery in Cesarean section (CS) plays an important role, particularly in reducing the maternal mortality rate (MMR) and infant mortality rates. Despite the reduction in the world MMR point of estimate from 342/100,000 births in 2000 to $211 / 100,000$ births in 2017 [6], the MMR in Indonesia in 2015 is still 305/100,000 births [7]. Most CS procedures in teaching hospitals involve residents to advance their skills. Therefore, appropriate supervision for their development and the 
assurance of patient safety is needed. A resident must carry out 10-15 CS procedure before considered ready to perform independently [8], [9]. Senior obstetricians may need to provide guidance to trainees during their first 15 independent CS procedures [8]. One study stated that on average, a resident's skill reached the level of an independent surgeon after performing about 30 operations [10], while another found that 20 procedures is adequate experience to ensure sufficient patient safety [11]. In Argentina, the risk of maternal death increased by 5.5 times in hospitals without a residency program [12]. There are few reports on the analysis of resident supervision in satellite hospitals; hence, analyzing supervision appropriateness has also been challenging. Therefore, this study aims to obtain an overview of resident supervision in conducting CS and the achievement of quality services to conduct hospital accreditation standards. The research questions are: (1) How has the supervision of CS procedures been carried out in the current satellite teaching hospital and (2) how do the residents conduct supervised services according to hospital accreditation standards?

\section{Materials and Methods}

\section{Context}

Fatmawati General Hospital is a satellite teaching hospital of the Faculty of Medicine, Universitas Indonesia. Obstetrics and Gynaecology residents work in this hospital for a period of one month in three stages: early, apprentice, and chief resident. The term early stage is given to residents in the second semester of the residency program, while the apprentice and chief residents stages include residents in their third to seventh and eighth and ninth semesters, respectively. Based on hospital policy, the levels of supervision refer to hospital accreditation standards, and these include high supervision, moderate-high supervision, moderate-low supervision, and low supervision [13]. We define high supervision as when a supervisor assists in every activity, and the evidence is supported by the supervisor's signature in the medical record. Moderate-high supervision is defined as when most of the resident activities are completed by the supervisor, while moderate-low supervision occurs when only some activities are completed by the supervisor. Supervision is categorized as low if the activities include no supervisor involvement.

CS indications are divided into six categories: CS without complication, CS and sterilization, CS with history of CS, CS in preterm <28 weeks, CS in a complex emergency case, and CS with placenta previa. Chief residents, who are in their eighth and ninth semesters, have reached level 5 competence in all procedures except CS in a complex emergency case, where they have reached level 4 competence. The competency level reached by early-stage residents in carrying out CS is level 1 , while it can be from level 1 to 4 for apprentice stage residents (third to seventhsemester resident).

\section{Data collection and analysis}

This study was a retrospective study with a cross-sectional design. The population for this study was all patients who underwent CS at Fatmawati General Hospital, Indonesia, in May 2020 with the involvement of Obstetrics and Gynecology Residents. The overall data for CS procedures were obtained from the Central Surgical Installation through the administrative officers, and they include patient name, medical record number, type of procedure, and name of the attending supervisor, including their role during the procedures. The inclusion criteria were all CS procedures that carried out by residents. CS which not involved resident were excluded from the study. Hospital services quality data were collected from the Medical Record and Data Center Installation manually and then entered into the table according to the coding that was previously prepared. The variables chosen in this study were based on hospital indicators. We assessed preoperative visit, completeness of education sheet, operation report signing, marked site accuracy, and post-operative visit. After all the data were collected, the calculation and a descriptive data analysis were conducted.

\section{Results}

Eight residents were included in this study, consisting of six apprentice-stage residents and two chief residents. All apprentice-stage residents were in the third semester of residency. The number of patients that underwent CS in May 2020 is 86 . Eleven of the 86 cases did not involve residents, therefore those cases were excluded. A reduction in the number of residents sent to the satellite teaching hospital during the coronavirus disease 2019 (COVID-19) pandemic led the consultants on duty to carry out some procedures alone, including some difficult cases for which the resident on duty was not yet at the proper competence level. The number of CS procedures performed by the residents was 75 , including $42(56 \%)$ conducted by chief residents and $33(44 \%)$ by apprentice-stage residents.

Table 1 shows the CS indications, as well as the supervision carried out. Some of the cases have more than one indication. Supervision during the procedure was carried out in 74 cases $(98.6 \%)$. Otherwise, the data revealed that during hospitalization, 25 cases $(33.3 \%)$ were given moderate-high, 39 cases $(52 \%)$ moderate-low, and 11 cases (14.7\%) low supervision. 
Table 1: Cesarean section supervision (obtained from $75 \mathrm{CS}$ reports on medical records)

\begin{tabular}{|c|c|c|c|c|c|c|c|c|c|c|c|c|c|c|c|}
\hline \multirow[t]{3}{*}{ Procedure } & \multirow{2}{*}{\multicolumn{3}{|c|}{ Operator }} & \multirow{2}{*}{\multicolumn{3}{|c|}{ History of SC }} & \multirow{2}{*}{\multicolumn{3}{|c|}{$\begin{array}{l}\text { Supervision during } \\
\text { hospitalization }\end{array}$}} & \multicolumn{6}{|c|}{ Supervision during procedure } \\
\hline & & & & & & & & & & \multicolumn{3}{|c|}{ Presence } & \multicolumn{3}{|c|}{ Absence } \\
\hline & $\mathrm{CR}$ & ASR & Total & $\overline{C R}$ & ASR & Total & $\begin{array}{l}\text { Moderate } \\
\text { high }\end{array}$ & $\begin{array}{l}\text { Moderate } \\
\text { low }\end{array}$ & Low & $\overline{C R}$ & ASR & Total & $\overline{C R}$ & ASR & Total \\
\hline Cesarean Section without complication & 8 & 6 & 14 & 3 & 3 & 6 & 7 & 5 & 2 & 7 & 6 & 13 & 1 & 0 & 1 \\
\hline Cesarean section with IUD & 22 & 21 & 43 & 5 & 8 & 13 & 15 & 24 & 4 & 22 & 21 & 43 & 0 & 0 & 0 \\
\hline Cesarean Section with sterilization & 7 & 5 & 12 & 5 & 4 & 9 & 2 & 8 & 2 & 7 & 5 & 12 & 0 & 0 & 0 \\
\hline Cesarean Section in preterm (less than & 1 & 0 & 1 & 0 & 0 & 0 & 0 & 0 & 1 & 1 & 0 & 1 & 0 & 0 & 0 \\
\hline \multicolumn{16}{|l|}{28 weeks), followed with IUD } \\
\hline Cesarean Section in complex emergency case & 4 & 1 & 5 & 2 & 1 & 3 & 1 & 2 & 2 & 4 & 1 & 5 & 0 & 0 & 0 \\
\hline Total & & & 75 & 15 & 16 & 31 & 25 & 39 & 11 & 41 & 33 & 74 & & & 1 \\
\hline
\end{tabular}

CR: Chief resident, ASR: Apprentice-stage resident

Most CS procedures without complication received moderate-high supervision (seven cases), and the others were given moderate-low (five cases) and low (two cases) supervision. Twenty-four of 43 CS procedures with IUD insertion received moderate-low supervision during hospitalization, while 15 received moderate-high and only four low supervision. All cases were assisted by supervisors during the procedures, which was proven by their presence. All CS procedures with sterilization were supervised directly during the procedure. Otherwise, during hospitalization, eight of 12 cases were given moderate-low, two cases low, and two cases moderate-high supervision.

Five case procedures were categorized as complicated, including three with a history of CS that required adhesiolysis, one with a history of two CS procedures in the past and a diagnosis of increta placenta requiring uterine resection and fimbrectomi, and one case of pregnancy with a transverse fetus requiring a cystectomy. Three of the patients undergoing these complicated procedures were suspected to have COVID-19. Four of the five complicated procedures were carried out by chief resident and only one by an apprentice-stage resident; however, supervisors were present during all procedures. Only one CS procedure was preterm, at $<28$ weeks, and this was performed by a chief resident with low supervision. CS with placenta previa, which is one of the six CS indications defined in this study, was not found.

To evaluate the quality of service of the CS procedures performed by residents, a closed medical record review was conducted. According to hospital accreditation standards, medical records should be completed by a resident and approved by the supervisor.

In total, 48 of 75 pre-operative visits ( $64 \%$ ) were carried out by residents. Unfortunately, 28 of 75 (37.3\%) with no approval from a supervisor; hence, 27 of 75 pre-operative visits $(36 \%)$ could not be identified due to lack of name and signature (Table 2). Patient education should be provided by doctors, including residents, and recorded by signing the education sheet. If patient education is given by a resident, it should be recorded by the supervisor as a consultant. Completeness of the education sheet were carried out in 59 of $75(78,6 \%)$ cases, consisting of 14 education sheets $(18.7 \%)$ were completed by the resident and approved by the supervisor, and 27 of 75 education sheets $(36 \%)$ with no approval from the supervisor. On the other hand,
18 of 75 education sheets showed that education was conveyed by the supervisor themself without resident involvement. Unfortunately, 16 of 75 education sheets $(21.3 \%)$ could not be identified due to lack of educator signature (Table 2).

Table 2: Completeness of CS medical record developed by residents and supervisors $(n=75)$

\begin{tabular}{|c|c|c|c|c|c|c|}
\hline \multirow[t]{2}{*}{$\begin{array}{l}\text { Signature on medical } \\
\text { record }\end{array}$} & \multicolumn{2}{|c|}{$\begin{array}{l}\text { Pre-operative } \\
\text { visit }\end{array}$} & \multicolumn{2}{|c|}{$\begin{array}{l}\text { Education sheet } \\
\text { filling }\end{array}$} & \multicolumn{2}{|c|}{$\begin{array}{l}\text { Surgery report } \\
\text { signature }\end{array}$} \\
\hline & Number & $\%$ & Number & $\%$ & Number & $\%$ \\
\hline Consultant & 2 & 2.7 & 18 & 24.0 & 51 & 68.0 \\
\hline Consultant and resident & 18 & 24.0 & 14 & 18.7 & 1 & 1.3 \\
\hline Only resident & 28 & 37.3 & 27 & 36.0 & 20 & 26.7 \\
\hline Lack of name and signature & 27 & 36.0 & 16 & 21.3 & 3 & 3.0 \\
\hline Total & 75 & 100 & 75 & 100 & 75 & 100 \\
\hline
\end{tabular}

The site should be marked by the operator prior to the procedure. According to hospital regulations, the agreed-upon mark for sites is an arrow on the medical record, as well as on the procedure location. Hence, it must be clear, not easily erased, and it should be done by the operator while the patient is still conscious. Sixtyfour of 75 marked sites ( $85.3 \%$ ) on medical records were considered the correct marked site. Sites were marked appropriately by 34 of $42(80.9 \%)$ chief residents and 30 of $33(90.9 \%)$ apprentice-stage residents (Table 3$)$.

Table 3: Marked site accuracy ( $n=75$ CS procedures)

\begin{tabular}{lllll}
\hline Marked site & Chief resident & $\begin{array}{l}\text { Apprentice stage } \\
\text { resident }\end{array}$ & Total & Percentage \\
\hline Appropriate marked site & 34 & 30 & 64 & 85,3 \\
Inappropriate marked site & 3 & 1 & 4 & 5,3 \\
Lack of marked site & 5 & 2 & 7 & 9,3 \\
Total & 42 & 33 & 75 & 100 \\
\hline
\end{tabular}

All operating activities should be recorded in the operation report sheet and signed by the operator and co-operator. Regardless of whether the resident or supervisor led the procedure, both should sign the operation report. In total, $68 \%$ of reports were signed by the consultant as the supervisor, while only $26.7 \%$ were signed by residents (Table 2).

A post-operative visit assessment aims to show whether a visit was carried out by residents every day. Forty-nine of 75 cases $(65.3 \%)$ were visited by residents, which 15 of 75 were not visited every day (20\%). Otherwise, we found five of 75 cases $(6.7 \%)$ that were visited by the consultant themselves while 21 of 75 cases $(28 \%)$ were visited by both resident and consultant (Table 4).

Table 4: Post-operative visit

\begin{tabular}{|c|c|c|c|c|c|c|c|c|}
\hline \multirow[t]{2}{*}{ Frequency of visiting } & \multicolumn{2}{|c|}{ Resident } & \multicolumn{2}{|c|}{ Consultant } & \multicolumn{2}{|c|}{$\begin{array}{l}\text { Consultant } \\
\text { and resident }\end{array}$} & \multicolumn{2}{|c|}{ Total } \\
\hline & $\mathrm{n}$ & $\%$ & $n$ & $\%$ & $\mathrm{n}$ & $\%$ & $\mathrm{n}$ & $\%$ \\
\hline Everyday & 34 & 45.3 & 0 & 0 & 9 & 12.0 & 43 & 57.3 \\
\hline Not everyday & 15 & 20.0 & 5 & 6.7 & 12 & 16.0 & 32 & 42.7 \\
\hline Total visit & 49 & 65.3 & 5 & 6.7 & 21 & 28 & 75 & 100 \\
\hline
\end{tabular}


Educational meetings and assessment were conducted in May 2020 to engage in five difficult case discussions, seven DOPS, six case-based discussions, six journal readings, and five report meetings to discuss all cases carried out by residents. Those meetings were conducted by the experts on each particular case. Feedback and evaluation were given to enrich their knowledge and experience, and report was conveyed to the faculty at the end of their station in satellite hospital.

\section{Discussion}

This study highlights that supervision during CS procedures was carried out beyond expectations, exceeding the stipulated amount of supervision, without considering the level of competence of the resident. Compared to the former data showing $6.5 \%$ procedures were unsupervised, supervisory assistance was provided consistently during the CS procedures, except in one case that was carried out by the chief resident. On the other hand, we found most of the supervision during hospitalization was moderate-high. Regarding the quality of service performed by the residents, this study shows that the achievement of quality service indicators is closely related to the procedure; for example, the number of surgery report signatures and correctly marked sites was higher than the achievement of pre-and post-operative quality service indicators.

Hospital regulations require consultants assigned as supervisors to be present outside of working hours to assist and supervise all residents, particularly during procedures. Resident supervision indicators are measured based on the presence of the operator, without considering resident competency in that procedure. A summative evaluation to identify whether trainees are considered capable, professional, and as having sufficient competence to carry out an activity is needed for entrustable professional activities [14]. Trainees who have been trusted and who are capable of conducting a clinical activity would not need close supervision [15]. The Faculty of Medicine, Universitas Indonesia, defined five levels of competence in conducting CS. This retrospective study was unable to show appropriate supervision based on these competency levels, which should be observed in real-time. Implementation of resident supervision in the hospital refers to hospital accreditation standards. Based on the data collected in the operating theater, almost all of the consultant were present during the procedure to supervise their residents in order to evaluate the residents' performance and to provide a comprehensive assessment.

Workplace-based assessments, such as the DOPS, Mini-CEX, and $360^{\circ}$ evaluation can be conducted to asses resident competency [4]. The
Accreditation Council of Graduate Medical Education provides six core competencies as a conceptual framework describing the required domains for a trusted physician, including residents, to enter autonomous practice [16]. These are needed in CS procedures as well, as they not only ensure competence in skills, but they also cover other supporting competences, such as medical knowledge, practice-based learning and improvement, interpersonal and communication skills, professionalism, and system-based practice [16]. Feedback in conducting resident assessments plays an important role in ensuring effective supervision [17]. Therefore, the assignments that have been carried out in May 2020 were case discussions, DOPS, and report meetings to discuss cases carried out by residents on duty. Difficult or interesting cases were presented by residents and discussed in a meeting attended by all staff, particularly the expert consultants. Other activities, such as case-based discussions and journal readings, have been accomplished as well. According to clinical meeting data on the Obstetrics and Gynecology Department of Fatmawati General hospital, topics to be discussed were different between one group of residents and another, depending on the cases. Discussions conducted on death cases, difficult cases, and cases requiring collaboration with other specialists or professionals were carried out to have broader insight and holistic management. On this occasion, supervisors and other consultants will provide feedback to the residents. When conducting interprofessional discussions, residents will gain much knowledge and experience, which is the objective of assigning residents to satellite hospitals. All meetings were reported to the faculty, as was resident performance during their station.

Medical records play an important role, not only for services but also for education and training. This study shows that quality standards during procedures attract supervisors' attention more than other variables that are not in high-risk condition. Filling out medical records has not been accomplished yet in accordance with the quality standards setting. Although the residents have the authority to fill the medical records, hospital accreditation standards required supervisors' validation. This condition reflects how supervision was carried out in the teaching hospital in Indonesia. Therefore, these results could be the basis for further evaluations of resident supervision in providing service quality.

Finally, the resident must be able to demonstrate awareness of and responsiveness to the larger context and system of health care. Awareness of patient safety is needed to minimize the occurrence of risks and prevent medical errors, or undesirable events due to lack of examination or procedure that should be done. The World Health Organization stated that safe surgery is a patient safety standard [18]. In Indonesia, this statement is issued by the Ministry of Health to be adhered to by 
all hospitals, including teaching hospitals [19]. The previous study proved that education for all health provider to increase the understanding of patient safety were needed, particularly in operating room [20].

We are aware of the limitations of this study. First, supervision level appropriateness was assessed based on medical records only. While this is still valid, supervision implementation should be observed, followed by a discussion to clarify. This would be more appropriate, and it should be one of the critical points for future study. The development of a comprehensive supervision monitoring system is thus thought to assist in the implementation of proper supervision. Understanding of patient safety including the achievement of quality service indicators, particularly in services carried out by residents, is the expected impact of appropriate supervision.

\section{Conclusions}

Supervision during CS procedures was provided directly as well as by conducting case discussions. Medical record assessment plays an important role in evaluating the quality of services provided by residents, in accordance with hospital accreditation standards. Developing a comprehensive supervision system is required to achieve resident competencies and good quality service in satellite teaching hospitals.

\section{Acknowledgment}

This study was supported by the Directorate of Research and Development, the University of Indonesia under PUTI Doktor 2020. The sponsor was not involved in study design, data collection, analysis and interpretation of data, writing the report, and the decision to submit the article for publication.

\section{References}

1. Fatmawati General Hospital. Fatmawati General Hospital Services Data $1^{\text {st }}$ Trimester. Jakarta, Indonesia: Data Pelayanan Triwulan I Tahun 2020 RSUP Fatmawati; 2020.

2. Launer J. Supervision, mentoring and coaching. In: Swanwick T, Forrest K, O'Brien B, editors. Understanding Medical Education. $3^{\text {rd }}$ ed. Oxford: Wiley Blackwell; 2018. p. 179-90.

3. Peters H, Holzhausen Y, Boscardin C, Ten Cate O, Chen HC. Twelve tips for the implementation of EPAs for assessment and entrustment decisions. Med Teach. 2017;39(8):802-7. https:// doi.org/10.1080/0142159X.2017.1331031

\section{PMid:28549405}

4. Wragg A, Wade W, Fuller G, Cowan G, Mills P. Assessing the performance of specialist registrars. Clin Med (Northfield II). 2003;3(2):131-4. https://doi.org/10.7861/clinmedicine.3-2-131 PMid:12737369

5. Norcini J, Zaidi Z. Workplce assessment. In: Swanwick T, Forrest K, O'Brien B, editors. Understanding Medical Education. $3^{\text {rd }}$ ed. Oxford: Wiley Blackwell; 2018. p. 319-34.

6. World Health Organization. Trends in Maternal Mortality 2000 To 2017, Estimates by WHO, UNICEF, UNFPA, World Bank Group and The Unaited Nations Population Division. Geneva: World Health Organization; 2019.

7. Ministry of Health of Republic of Indonesia. In: Haardhana B, Sibuea F, Widiantini W, editors. Health Profil Year 2019. Ministry of Health of Republic of Indonesia; 2020. p. 98-113.

8. Fok WY, Chan LY, Chung TK. The effect of learning curve on the outcome of caesarean section. BJOG 2006;113:1259-63.

9. Soergel P, Jensen T, Makowski L, Von Kaisenberg C, Hillemanns P. Characterisation of the learning curve of caesarean section. Arch Gynecol Obstet 2012;286:29-33.

10. Eledessy MS, Olma M, Elmraghy Y. Quality assessment of resident for caesarean sectio in Assiut. AAMJ. 2009;7(2):125-36.

11. Müller I, Zimmermann R. Educational strategies in performing cesarean section. Gynakol Geburtshilfliche Rundsch. 2003;43(4):238-44

12. Ramos S, Karolinski A, Romero M, Mercer R. A comprehensive assessment of maternal deaths in Argentina: Translating multicentre collaborative research into action. Bull World Health Organ 2007;85(8):615-22. https://doi.org/10.2471/blt.06.032334 PMid: 17768520

13. Komisi Akreditasi Rumah Sakit. Hospital accreditation national standards. In: Sutoto, editor. Standar Nasional Akreditasi Rumah Sakit. $1^{\text {st }}$ ed. Jakarta, Indonesia: Komisi Akreditasi Rumah Sakit; 2019. p. 439-47.

14. Ten Cate O. Entrustability of professional activities and competency-based training. Med Educ. 2005;39(12):1176-7. https://doi.org/10.1111/j.1365-2929.2005.02341.x PMid: 16313574

15. Ten Cate O, Chen HC, Hoff RG, Peters H, Bok H, Van Der Schaaf M. Curriculum development for the workplace using Entrustable Professional Activities (EPAs): AMEE guide No. 99. Med Teach. 2015;37(11):983-1002. http://dx.doi.org/10.3109/01 42159X.2015.1060308 PMid:26172347

16. ACGME. Common Program Requirements. Acgme; 2007. p. 7250-7. Available from: http://www.acgme.org/Portals/0/ PFAssets/ProgramRequirements/CPRs_04012007.pdf [Last accessed on 2021 Jul 07].

17. Kilminster SU, Cottrell D, Grant J, Jolly B. AMEE Guide No. 27: Effective Educational and Clinical Supervision; 2007. p. 2-19.

18. World Health Organization. WHO Guidelines for Safe Surgery. Geneva: World Health Organization; 2009. Available from: http://apps.who.int/iris/bitstream/ handle/10665/44185/9789241598552_eng.pdf;jsessionid=A38 53CA0EF87FF8 39FF7370064 11B80A?sequence $=1$. Published 2009 [Last accessed on 2020 Jan 13]

19. Kementerian Kesehatan Republik Indonesia. Regulation of the Minister of Health of the Republic of Indonesia Number 11 Concerning Patient Safety. Vol. 53. Kementerian Kesehatan Republik Indonesia; 2017. p. 130.

20. El-Shafei AM, Ibrahim SY, Tawfik SM, Abd El Fatah SA. World Health Organization safety surgery checklist with addition of infection control items: Intervention study in Agypt. Open Access Maced J Med Sci. 2019;7(21):3691-7. https://doi.org/10.3889/ oamjms.2019.593

PMid:32010400 